\title{
Adverse Drug Reaction Monitoring of Antipsychotic Drugs and Mood Stabilizers in a Teaching Hospital
}

\author{
Swetha Munoli ${ }^{1}$, Soumya B Patil ${ }^{\star}$ \\ ${ }^{1}$ Department of Pharmacology, ESIC-MC \& PGIMSR, Bangalore, Karnataka, INDIA. \\ ${ }^{2}$ Department of Pharmacology, Navodaya Medical College, Raichur, Karnataka, INDIA.
}

\begin{abstract}
Background: Antipsychotics and mood stabilizers are associated with adverse effects which can affect the compliance and course of treatment in mental disorders. The present study was therefore undertaken to monitor the adverse drug reactions (ADRs) of the antipsychotics and mood stabilizers in the psychiatric outpatient unit of our hospital. Methods: Study was conducted from December 2011 to November 2012, the patients on antipsychotic drugs from psychiatry outpatient department (OPD) of Raichur Institute of Medical Sciences were considered for analysis. The patients were diagnosed by consultant psychiatrist. Data was collected in standard questionnaire format. All patients diagnosed with psychiatric disorder as per ICD 10 criteria and receiving treatment with antipsychotic or mood stabilizer were included. Assessment of causality and severity of recorded adverse events was done using WHO assessment scale and modified Siegel and Hartwig Scale respectively. Results: 45 ADRs were recorded among 778 patients. Extra pyramidal symptoms, anticholinergic side effects and Weight gain were the most common ADRs. Risperidone, chlorpromazine and olanzapine were the drugs causing maximum ADRs. Assessment of causality and severity of recorded adverse events showed possible to probable and mild to moderately severe respectively. Conclusion: Extrapyramidal symptoms were most common ADRs in our study followed by anticholinergic side effects. Risperidone was most commonly prescribed drug followed by chlorpromazine. Risperidone and chlorpromazine accounted for most of ADRs. Assessment of causality of recorded adverse events showed no certain cause and Assessment of severity of recorded adverse events showed no severe cases.
\end{abstract}

Key words: Antipsychotics, Olanzapine, Risperidone, Extrapyramidal Symptoms, Lithium, Haloperidol.

Citation: Munoli S, Patil SB. Adverse Drug Reaction Monitoring of Antipsychotic Drugs and Mood Stabilizers ina Teaching Hospital. Int J Pharmacol and Clin Sci. 2016;5(4):118-21.

\section{INTRODUCTION}

According to WHO, adverse drug reaction is defined as "Any response to a drug which is noxious and unintended, and which occurs at doses normally used in man for prophylaxis, diagnosis, or therapy of disease, or for the modification of physiological function" ${ }^{[1]}$ Adverse drug reactions (ADRs) are known to be the significant cause of morbidity and mortality both inpatients and outpatients settings. ${ }^{[2]}$ The overall incidence of serious and fatal ADRs among hospitalized patients was found to be $6.7 \%$ and $0.32 \%$, respectively. ${ }^{[3]}$ While in outpatient settings, the incidence of ADRs ranges from $5 \%$ to $35 \%{ }^{[4]}$ ADRs are recognized to be one the significant cause of hospital admissions and the incidence varied from $0.2 \%$ to $41.3 \% .^{[5]}$

Pharmacovigilance, the science and activities related to the detection, assessment, understanding and prevention of adverse effects or any drug related problem, is highly essential in India, where there is lack of adequate safety related data for drugs in general and psychotropic agents in particular. India seems to rate below 1\% in ADR reporting, as against the world rate of $5 \%{ }^{[6]}$

Psychotropic drugs are plentiful in number and their use is increasing day by day. These drugs are capable of causing a

Received : 7-12-2016 Revised : 27-12-2016;

Accepted : 30-12-2016

*Correspondence : Dr Soumya B Patil,

Department of Pharmacology, Navodaya Medical College,

Raichur, Karnataka, INDIA

E-mail: sou_doc@yahoo.co.in

Conflict of interest: Nil ; Source of support : Nil

Copyright: ${ }^{\odot} 2016$ Journal. All rights reserved.

DOI : 10.5530/ijpcs.5.4.5 
number of adverse drug reactions (ADR), ${ }^{[7,8]}$ some of which may be fatal. ${ }^{[9]}$ ADRs associated with psychotropic drugs can lead to noncompliance, and at times discontinuation of therapy. ${ }^{[10]}$ Pharmacovigilance in psychiatry units can play a vital role in detecting ADRs and alerting physicians to the possibility and circumstances of such events, thereby protecting the user population from avoidable harm. ${ }^{[1]}$ Hence we conducted the study with the objectives to do surveillance and detect incidence of adverse drug reactions (ADRs) in outpatient department of Psychiatry, to access and analyze the ADRs according to their demographic distribution, reporting and presentations and to do causality and severity analysis of ADRs.

\section{METHODS}

A longitudinal observational study was conducted in patients attending outpatient department of psychiatry at Raichur Institute of Medical Sciences. The study was approved by institutional ethics committee.

\section{Study period}

December 2011 to November 2012.

\section{Inclusion criteria}

Patient visiting the psychiatry OPD and receiving antipsychotic drugs or mood stabilizers with a diagnosis of psychiatric illness as per ICD 10 criteria and patients above age of 12 years

\section{Exclusion criteria}

Diagnosed cases of mental retardation and dementia and patients on stimulant drugs.

Patient information were recorded in CDSCO Adverse Drug Reaction reporting form, Assessment of causality and severity was done using WHO assessment scale and modified Siegel and Hart wig Scale respectively.

\section{RESULTS}

Incidence of ADRs was 5.2\%, 45 ADRs were recorded among 41 cases, 778 patients were screened, among 41 cases 23 were male and 18 were female. Extra pyramidal symptoms (15), anticholinergic side effects (10) and Weight gain (8) were the most common ADRs. Risperidone (22), chlorpromazine (9) and olanzapine (7) were the drugs causing maximum ADRs. Assessment of causality and

\begin{tabular}{|c|c|c|c|}
\hline Name of drug & $\begin{array}{l}\text { Total no of } \\
\text { patients }\end{array}$ & $\begin{array}{l}\text { Total } \\
\text { cases of } \\
\text { ADRs }\end{array}$ & $\begin{array}{c}\text { Incidence } \\
\text { rate (\%) }\end{array}$ \\
\hline Risperidone & 372 & 22 & 5.91 \\
\hline Chlorpromazine & 227 & 9 & 3.96 \\
\hline Haloperidol & 54 & 1 & 1.85 \\
\hline Olanzapine & 55 & 7 & 12.72 \\
\hline Clozapine & 39 & 1 & 2.56 \\
\hline Lithium & 31 & 1 & 3.22 \\
\hline
\end{tabular}

\begin{tabular}{ccccc}
\multicolumn{2}{c}{ Table 2: Gender wise distribution of ADR cases. } \\
Drug & & Male & Female & Total \\
Antipsychotic & Atypical & 14 & 16 & 30 \\
& Typical & 8 & 2 & 10 \\
Mood stabilizer & 1 & 0 & 1 \\
Total & 23 & 18 & 41
\end{tabular}

$\begin{array}{ccccccc}\begin{array}{c}\text { Table 3: Age wise distribution of ADR cases } \\ \text { Drug }\end{array} & 12-<\mathbf{2 1} & \mathbf{2 1 - < 4 1} & \mathbf{4 1 - < 6 1} & >61 & \text { Total } \\ \text { Antipsychotic Atypical } & 3 & 24 & 1 & 2 & 30 \\ & \text { Typical } & 0 & 7 & 3 & 0 & 10 \\ \text { Mood stabilizer } & 0 & 1 & 0 & 0 & 1 \\ \text { Total } & 3 & 32 & 4 & 2 & 41\end{array}$

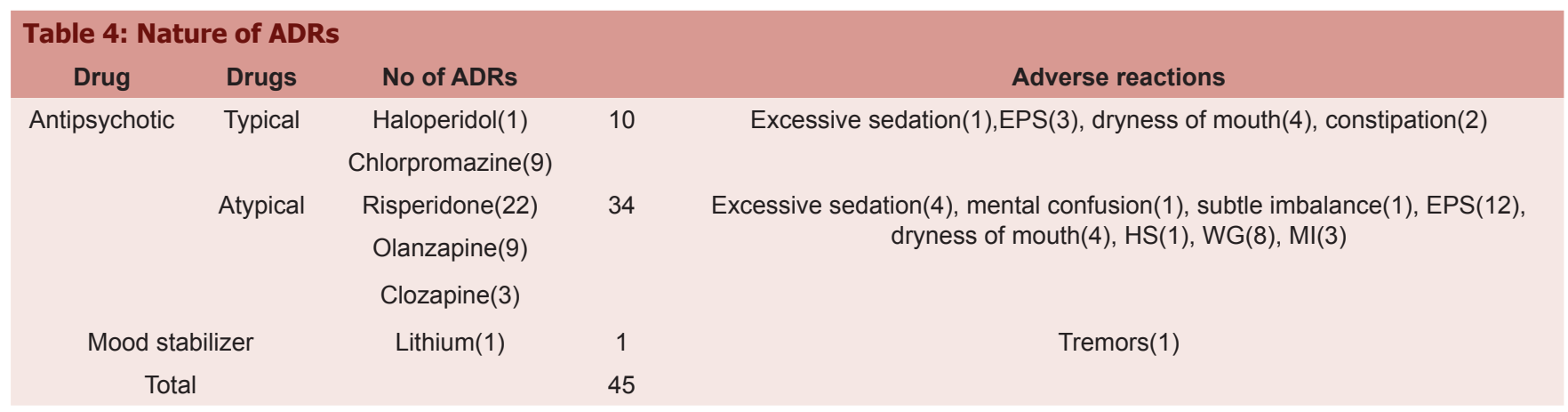

EPS: extrapyramidal symptoms, HS: hypersalivation, WG: weight gain, MI: menstrual Irregularity. 


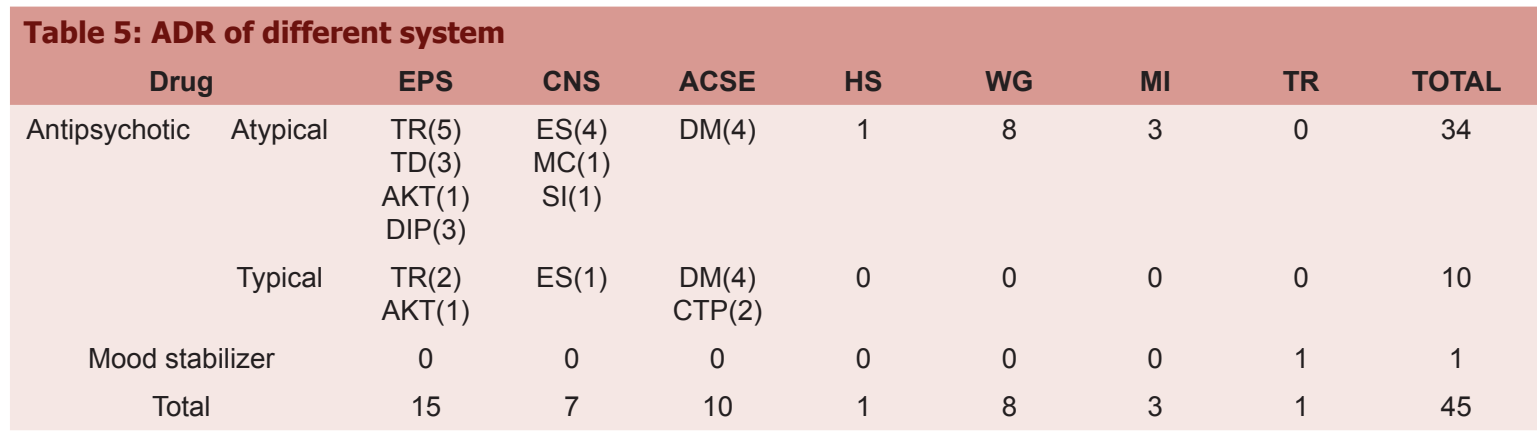

EPS-Extrapyramidal Symptoms, TR-tremors, TD-tardive dyskinesia, AKTakathisia, DIP-drug induced Parkinsonism, ES-Excessive sedation, MC-mental confusion, SI-subtle imbalance, ACSE- anticholinergic side effects, CTP-constipation, DM-dryness of mouth, HS-hypersalivation, WG-weight gain, MI-mentrual irregularity

\begin{tabular}{cccccc}
\multicolumn{4}{c}{ Table 6: Causality assessment of ADRs (WHO scale) } \\
Drug & & Certain & Probable & Possible & Total \\
Antipsychotic & Atypical & 0 & 12 & 18 & 30 \\
& Typical & 0 & 3 & 7 & 10 \\
Mood & & 0 & 0 & 1 & 1 \\
$\begin{array}{c}\text { stabilizer } \\
\text { Total }\end{array}$ & 0 & 15 & 26 & 41
\end{tabular}

severity of recorded adverse events showed possible to probable and mild to moderateseverity respectively (Table $1-7)$.

\section{DISCUSSION}

The overall incidence rate of ADRs in our study was found to be $5.2 \%$. Many international studies have reported an overall incidence rate of $5.01-21.45 \%$ in psychiatry OPDs. ${ }^{[12-16]}$ There were more male patients who developed ADRs, this is in contrast to the findings of previous studies ${ }^{[17,18]}$ and similar to a study by Sengupta et al, and Jain, et al where more males developed ADRs than females. ${ }^{[12-19]}$ 32 out of these 41 patients belonged to 21-40 years age group. Previous studies have quoted mean age of patients with ADRs within the range observed in our study. ${ }^{[12,19]}$ The most common antipsychotic drugs associated with ADR was risperidone followed by chlorpromazine and olanzapine. These drugs were most commonly prescribed in our psychiatry unit. A similar study done in IPGMER, Kolkata IN 2011 showed olanzapine as commonest drug causing ADR ${ }^{[12]}$ Among mood stabilizers lithium was more commonly prescribed unlike other study where valproate was more commonly prescribed drug. ${ }^{[21]}$ Extrapyramidal Symptoms, anticholinergic side effects and weight gain were most common ADRs observed in our study in decreasing order of their occurrence. Extrapyramidal Symptoms was also seen with second generation antipsychotics in our study as they were prescribed more commonly in our psychiatry OPD. Sengupta et al had

\begin{tabular}{|cccccc|}
\multicolumn{2}{l}{$\begin{array}{l}\text { Table 7: Severity of ADR cases } \\
\text { Drug }\end{array}$} & Mild & Moderate & Severe & Total \\
\hline Antipsychotic & Atypical & 18 & 12 & 0 & 30 \\
& Typical & 7 & 3 & 0 & 10 \\
$\begin{array}{c}\text { Mood } \\
\text { stabilizer }\end{array}$ & 1 & 0 & 0 & 1 \\
Total & & 26 & 15 & 0 & 41 \\
\hline
\end{tabular}

also found that neurological ADRs (tremors) were the most common ADRs followed by metabolic (weight gain) and gastrointestinal effects (constipation). ${ }^{[12]}$ Causality assessment was done and no "certain" causes were seen since in cases where dechallenge was done, rechallenge was not attempted with the offending drug. This is in contrast to a brazilian study where 23 cases were found to be "definite" after rechallenge was attempted. ${ }^{[20]}$ All ADRs reported were of mild to moderate severity. Study in India by Jose J et al ${ }^{[22]}$ showed mild and moderate reactions accounted for 50.5\% and $43.9 \%$ respectively. Grohmann $\mathrm{R}$ et al ${ }^{[23]}$ conducted study in Germany in 2004 and showed that severe ADRs due to psychopharmacological agents occurred in 1.4\% of exposed patients. The difference in the severity of ADRs might be due to difference in prescribing preferences at the different hospitals and there may be difference in the demographic characteristics of patients.

\section{CONCLUSION}

Extrapyramidal symptoms were most common ADRs in our study followed by anticholinergic side effects. Risperidone was most commonly prescribed drug followed by chlorpromazine. Risperidone and chlorpromazine accounted for most of ADRs. Assessment of causality of recorded adverse events showed no certain cause and Assessment of severity of recorded adverse events showed no severe cases. 


\section{CONFLICT OF INTEREST}

Nil

\section{REFERENCES}

1. Srinivasan R, Ramya G. Adverse drug reaction-causality assessment. Int J Res Pharm Chem. 2011;1(3):606-12.

2. Hakkarainen KM, Hedna K, Petzold M, Hägg S. Percentage of patients with preventable adverse drug reactions and preventability of adverse drug reactions-a meta-analysis. PloS one. 2012;7(3):e33236.

3. Lazarou J, Pomeranz BH, Corey PN. Incidence of adverse drug reactions in hospitalized patients: a meta-analysis of prospective studies. Jama. 1998;279(15):1200-5.

4. Budnitz DS, Pollock DA, Weidenbach KN, Mendelsohn AB, Schroeder TJ, Annest JL. National surveillance of emergency department visits for outpatient adverse drug events. JAMA.2006;296:1858-66.

5. Beijer HJ, De Blaey CJ. Hospitalisations caused by adverse drug reactions (ADR): a meta-analysis of observational studies. Pharmacy World and Science. 2002;24(2):46-54.

6. Lingeswaran A, Shetty H, Lahon K, Paramel A, Sharma G. Pharmacovigilance on olanzapine. Indian Journal of Pharmacology. 2010;42(4):252.

7. Aronson JK. Risk perception in drug therapy. British Journal of Clinical Pharmacology. 2006;62(2):135-7.

8. Rani FA, Byrne PJ, Murray ML, Carter P, Wong IC. Paediatric atypical antipsychotic monitoring safety (PAMS) study. Drug safety. 2009;32(4):325-33.

9. Glassman AH, Bigger Jr JT. Antipsychotic drugs: prolonged QTC interval, torsade de pointes, and sudden death. American Journal of Psychiatry. 2001;158(11):1774-82.

10. Cooper $C$, Bebbington $P$, King M, Brugha T, Meltzer H, Bhugra $D$, et al. Why people don't take their psychotropic drugs as prescribed: Results of the 2000 National Psychiatric Morbidity Survey. ActaPsychiatrScand 2007; 116:47-53.

11. Faich GA. US adverse drug reaction surveillance 1989-1994. Pharmacoepidemiology and drug safety. 1996;5(6):393-8.
12. Sengupta G, Bhowmick S, Hazra A, Datta A, Rahaman M. Adverse drug reaction monitoring in psychiatry out-patient department of an Indian teaching hospital. Indian Journal of Pharmacology. 2011;43(1):36.

13. Haddad PM, Sharma SG. Adverse effects of atypical antipsychotics: Differential risk and clinical implications. CNS Drugs. 2007;21:911 36.

14. Prajapati HK, Joshi ND, Trivedi HR, Parmar MC, Jadav SP, et al. Adverse drug reaction monitoring in psychiatric outpatient department of a Tertiary Care Hospital.

15. Mishra S, Swain TR, Mohanty M, Gyawali S, Khan GM, et al. Adverse Drug Reaction Monitoring of Antidepressants in the Psychiatry Outpatients Department of a Tertiary Care Teaching Hospital. 1131-4.

16. Solanke B, Mahatme MS, Dakhale G, Hiware S, Shrivastava $\mathrm{M}$, et al. Adverse drug reaction profile at psychiatry out-patient department of a tertiary referral centre in Central India. Int J Basic ClinPharmacol. 2013;2:341-3.

17. Davies EC, Green CF, Mottram DR,Pirmohamed M. Adverse drug reactions in hospitals: A narrative review. Curr Drug Saf. 2007;2:79-87.

18. Yonkers KA, Kando JC, Cole JO, Blumenthal S. Gender differences in pharmacokinetics and pharmacodynamics of psychotropic medication. The American journal of psychiatry. 1992.

19. Jain $T$, Bhandari $A$, Ram V, Parakh M, Wal $P$, et al. Drug interactions and adverse drug reactions in hospitalized psychiatric patients: $A$ critical element in providing safe medication use. Ger. J. Psychiatry. 2011;14:26-34

20. Carlini EL, Nappo SA. The pharmacovigilance of psychoactive medications in Brazil. Revista Brasileira de Psiquiatria. 2003;25(4):200-5.

21. Lahon KI, Shetty HM, Paramel AM, Sharma GY. Adverse drug reaction monitoring of anti-psychotics, anti-depressants and mood stabilizers in the psychiatric outpatient unit of a teaching hospital-a retrospective study. Int J Pharma Bio Sci. 2012;3:470-8.

22. Jose J, Rao PG. Pattern of adverse drug reactions notified by spontaneous reporting in an Indian tertiary care teaching hospital. Pharmacological Research. 2006;54(3):226-33.

23. Grohmann R, Hippius $H$, Helmchen H, Rüther E, Schmidt LG. The AMÜP study for drug surveillance in psychiatry-a summary of inpatient data. Pharmacopsychiatry. 2004;37(S 1):16-26. 